\title{
The Outer Membranes of Brucella spp. Are Not Barriers to Hydrophobic Permeants
}

\author{
G. MARTÍNEZ DE TEJADA AND I. MORIYÓN* \\ Departamento de Microbiologia, Universidad de Navarra, Apartado 273, \\ 31080 Pamplona, Spain
}

Received 18 February 1993/Accepted 27 May 1993

\begin{abstract}
The patterns of susceptibility to hydrophobic and hydrophilic drugs and the uptake of the fluorescent probe $N$-phenyl-naphthylamine in Brucella spp., Haemophilus influenzae, Escherichia coli, and deep rough Salmonella minnesota mutants were compared. The results show that the outer membranes of smooth and naturally rough Brucella spp. do not represent barriers to hydrophobic permeants and that this absence of a barrier relates at least in part to the properties of Brucella lipopolysaccharide.
\end{abstract}

Gram-negative bacteria have a cell envelope with a cytoplasmic membrane, a periplasmic compartment, and an outer membrane (OM). The OM contains phospholipids, proteins, and a characteristic lipopolysaccharide (LPS) located in the outer leaflet. The distribution and molecular properties of LPS, phospholipids, and porin proteins play a key role in both the protection against some harmful agents and the access of substances to the periplasmic space and transport systems (14). Hydrophilic solutes of appropriate molecular characteristics penetrate the OM through porins, and harmful agents that bind to lipid A of the LPS weaken the OM barrier and penetrate via the self-promoted pathway $(6,14)$. Moreover, uptake of hydrophobic substances can happen by partition into the lipid phase of the OM, but in most gram-negative bacteria this hydrophobic pathway is not accessible $(6,7,14)$. The few exceptions described include the genera with O-chain-lacking LPSs (i.e., Neisseria and Haemophilus) (6-8) and some deep rough mutants of enteric bacteria (14).

Brucella spp. are facultative intracellular pathogens of both humans and animals. The genus includes species with typical smooth LPS (Brucella abortus, B. melitensis, B. suis, and $B$. neotomae) along with others (B. ovis and $B$. canis) that lack the $O$ chain and that are usually designated naturally rough brucellae because of their similarity with the true rough mutants (3). Porins in Brucella spp. have been characterized and shown to have sieving properties similar to those of Escherichia coli OmpF (4), but evidence for other uptake pathways is only indirect $(4,10)$. Here, we present evidence for an accessible hydrophobic pathway in the OMs of $B$. abortus, B. melitensis, $B$. suis, and $B$. ovis.

The susceptibilities to hydrophilic and hydrophobic drugs of $B$. abortus 2308 (smooth, biotype 1, and virulent), B. ovis REO 198 (avirulent and $\mathrm{CO}_{2}$ independent), $E$. coli $0111 \mathrm{~K} 58$ H2, Haemophilus influenzae 9193 (a clinical isolate of serovar b), and rough Salmonella minnesota $\mathrm{Rd}_{1} \mathrm{p}^{+}$and $\mathrm{Re} 595$ (heptoseless) (1) were examined by standard procedures. The drugs used were those of groups I (hydrophilic) and II (hydrophobic) as defined by Nikaido (13), since increased susceptibility to group II is likely to reflect a functional hydrophobic pathway (13). Although there were differences between naturally rough $B$. ovis and smooth $B$. abortus, both showed a pattern of susceptibility to group II compounds

\footnotetext{
* Corresponding author.
}

close to that of $H$. influenzae 9193 and $S$. minnesota $\operatorname{Re} 595$ but different from that of $E$. coli 0111 K58 H2 (Table 1). These results can be taken as indirect evidence for a functional hydrophobic pathway (7).

Direct proof was obtained by using viable cells and $N$-phenyl-naphthylamine (NPN), a fluorescent probe whose quantum yield increases upon transfer from a hydrophilic to a hydrophobic environment (17) and which has been used in OM permeation studies (16). Exponentially growing cells were harvested (centrifuged for $10 \mathrm{~min}$ at $5,000 \times g$ at $20^{\circ} \mathrm{C}$ ), resuspended in $1 \mathrm{mM} \mathrm{KCN}-10 \mathrm{mM}$ phosphate-buffered saline $(\mathrm{pH} \mathrm{7.2)}$ at an optical density $(600 \mathrm{~nm})$ of $0.48(370 \mu \mathrm{g}$ [dry weight] $/ \mathrm{ml}$ ), and transferred to $1-\mathrm{cm}$-diameter fluorimetric cuvettes. NPN ( $500 \mu \mathrm{M}$ in acetone) was added after 15 to $20 \mathrm{~s}$ to a final concentration of $10 \mu \mathrm{M}$. Fluorescence was monitored at $20^{\circ} \mathrm{C}$ with an LS-50 fluorimeter (Perkin-Elmer Ltd., Beaconsfield, England) set as follows: excitation, 350 $\mathrm{nm}$; emission, $420 \mathrm{~nm}$; and slit widths, $2.5 \mathrm{~nm}$ (16). Whereas only a small increase in fluorescence (up to 25 relative fluorescence units [RFU]) was observed with $E$. coli 0111 $\mathrm{K} 58 \mathrm{H} 2$, a progressive and greater increase (up to $125 \mathrm{RFU}$ ) was obtained with $B$. abortus 2308 (Fig. 1A), showing that the level of NPN uptake was much higher in smooth $B$. abortus than in bacteria with an efficient barrier to hydrophobic permeants. The $S$. minnesota Re595 heptoseless mutant (1) also took up NPN (Fig. 1B), but the fluorescence increase (75 RFU) was less than that obtained with $B$. abortus 2308. Significantly, the increases in NPN fluorescence obtained with $B$. abortus 2308 and $B$. abortus RB51 (a stable rough mutant of 2308 ) were similar (Fig. 1), and the same results were also obtained with $B$. melitensis $16 \mathrm{M}$ (smooth, biotype 1, and virulent) and $B$. melitensis 115 (rough and avirulent) (data not shown). Other Brucella species yielded slightly different results, since with $B$. suis 2 the final fluorescence levels were higher (up to 160 RFU) and both a higher fluorescence level (175 RFU) and a faster NPN uptake were observed with $B$. ovis REO 198 (Fig. 1B). These differences within the genus could relate to quantitative differences in lipid composition and, in the case of $B$. ovis, to an even less effective barrier. Despite these species differences, the data show that NPN uptake by Brucella spp. does not relate to the presence or absence of the LPS O chain or to possible changes in the OM that could be indirectly brought about by the rough mutation (14).

NPN uptake in Brucella spp. and $H$. influenzae, a species that has been described as showing a hydrophobic pathway, 
TABLE 1. MICs of hydrophilic and hydrophobic agents

\begin{tabular}{|c|c|c|c|c|c|c|}
\hline \multirow{3}{*}{$\begin{array}{l}\text { Group and agent (partition } \\
\text { coefficient) }\end{array}$} & \multicolumn{6}{|c|}{ MIC $(\mu \mathrm{g} / \mathrm{ml})$ for: } \\
\hline & \multirow{2}{*}{$\begin{array}{l}\text { B. abortus } \\
2308\end{array}$} & \multirow{2}{*}{$\begin{array}{c}\text { B. ovis REO } \\
198\end{array}$} & \multirow{2}{*}{$\begin{array}{l}\text { H. influenzae } \\
9193\end{array}$} & \multicolumn{2}{|c|}{ S. minnesota } & \multirow{2}{*}{$\begin{array}{l}\text { E. coli } \mathrm{O} 111 \\
\mathrm{~K} 58 \mathrm{H} 2\end{array}$} \\
\hline & & & & $\mathrm{Rd}_{1} \mathrm{p}^{+}$ & Re595 & \\
\hline \multicolumn{7}{|l|}{ I (hydrophilic) } \\
\hline Penicillin (0.02) & 2.0 & 1.0 & 1.0 & 2.0 & 2.0 & $>8.0$ \\
\hline Ampicillin $(<0.01)$ & 1.0 & 0.5 & 1.0 & 0.5 & 0.5 & 4.0 \\
\hline Tetracycline $(<0.07)$ & $<2.0$ & $<2.0$ & $<2.0$ & $<2.0$ & $<2.0$ & $>16.0$ \\
\hline Cephalothin $(<0.01)$ & 8.0 & 64.0 & 8.0 & 4.0 & 4.0 & 16.0 \\
\hline Nafcillin $(0.31)$ & 128.0 & 8.0 & 32.0 & $>256.0$ & $>256.0$ & $>256.0$ \\
\hline \multicolumn{7}{|l|}{ II (hydrophobic) } \\
\hline Erythromycin & 8.0 & $<0.1$ & 4.0 & $>16.0$ & 4.0 & $>16.0$ \\
\hline Rifampin (8.8) & 2.0 & $<0.5$ & $<0.5$ & 4.0 & $<0.5$ & $>4.0$ \\
\hline Novobiocin $(>20)$ & 16.0 & 0.5 & $<0.2$ & 32.0 & 16.0 & 128.0 \\
\hline Crystal violet (14.4) & 16.0 & $<0.2$ & 16.0 & 8.0 & 2.0 & 64.0 \\
\hline
\end{tabular}

${ }^{a}$ Partition coefficients in 1-octanol-0.05 $\mathrm{M}$ sodium phosphate (pH 7.0) at $24^{\circ} \mathrm{C}$ (taken from reference 14).

was compared. As judged from the fluorescence increase, the kinetics of NPN uptake in $H$. influenzae 9193 and in the Brucella strains tested, with the exception of $B$. ovis REO 198, were similar (Fig. 1). In addition, differences in final fluorescence levels were also observed. When the experiments were repeated with cells with envelopes disrupted by boiling, NPN uptake was instantaneous but the final fluorescence did not change substantially (Fig. 1), proving that the
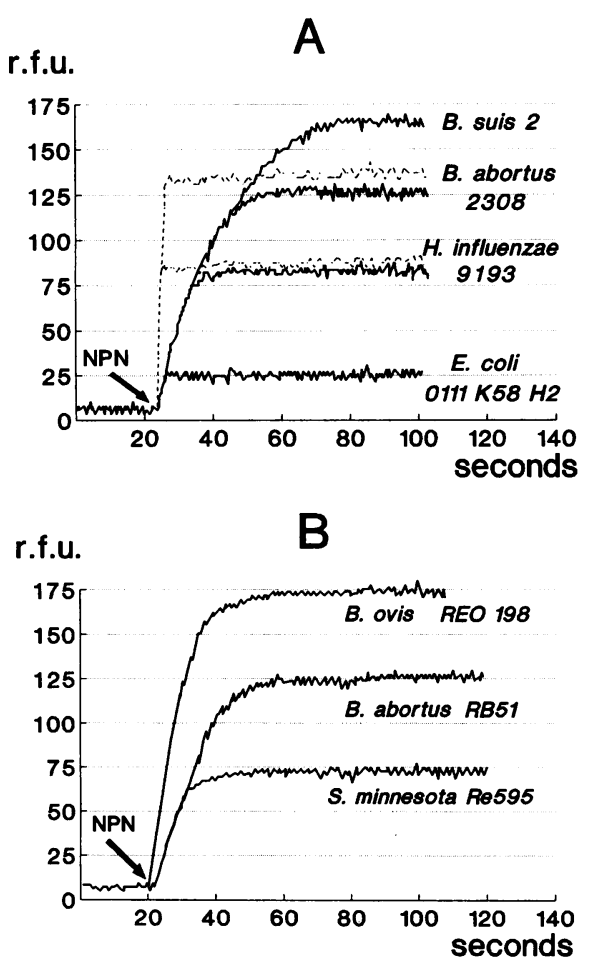

FIG. 1. Uptake of NPN by whole bacterial cells of smooth strains $E$. coli 0111 K58 H2, H. influenzae $9193, B$. abortus 2308, and $B$. suis 2 (A) and rough strains $S$. minnesota $\operatorname{Re} 595$ (heptoseless mutant), B. abortus RB51 (rough mutant of $B$. abortus 2308), and $B$. ovis REO 198 (naturally rough species) (B). Discontinuous lines in panel A represent results with boiled $H$. influenzae 9193 and $B$. abortus 2308 . kinetics of uptake by viable cells reflected the integrity of the $\mathrm{OM}$ and that the final fluorescence levels represented the saturation of the envelope lipid with the probe. Thus, it seems possible that the differences in final fluorescence between $H$. influenzae and Brucella spp. might reflect quantitative and/or qualitative differences in lipid composition. These results show that, as in $S$. minnesota deep rough mutants and in $H$. influenzae, the OM does not act as a barrier to hydrophobic permeants in Brucella spp., with the particularity that this property is shared by cells with rough and smooth LPSs.

An enhanced hydrophobic uptake could result from decreased LPS-to-LPS interactions through weaker binding of divalent cations (6). If so, agents that remove divalent cations should have little or no effect on NPN uptake by Brucella spp. Figure 2 shows that exposure to $5 \mathrm{mM}$ EDTA increased the NPN uptake by $E$. coli $0111 \mathrm{~K} 58 \mathrm{H} 2$. On the other hand, neither the kinetics of NPN uptake by $B$. abortus 2308 nor the final fluorescence values were modified by EDTA, and the same observations were made with $B$. melitensis $16 \mathrm{M}$ and $B$. suis 2 (data not shown). This is consistent with the absence of divalent-cation stabilization of LPS in the OM of Brucella spp. postulated before (12) and with the comparatively reduced proportions of anionic groups (phosphate and 2-keto-3-deoxyoctonic acid) in $B$. abortus LPS (11).

The results described above confirm the prediction by Martin and Hancock (10) that the susceptibility of Brucella spp. to erythromycin and rifampin should reflect an accessible hydrophobic pathway. Moreover, the results link this hydrophobic pathway to the properties of the LPS. Thus, the LPSs of $E$. coli $0111 \mathrm{~K} 58 \mathrm{H} 2$ and $B$. abortus 2308 were extracted with phenol-water (9) and purified (by treatment with $1 \mu \mathrm{g}$ [each] of DNase and RNase per mg of LPS in 10 $\mathrm{mM}$ Tris-HCl-5 mM MgCl 2 for $4 \mathrm{~h}$ at $37^{\circ} \mathrm{C}$, treatment with 5 $\mu \mathrm{g}$ of proteinase $\mathrm{K}$ per $\mathrm{mg}$ of LPS for $24 \mathrm{~h}$ at $24^{\circ} \mathrm{C}$, and ultracentrifugation). By sodium dodecyl sulfate-polyacrylamide gel electrophoresis and silver or periodate-silver stain (18), both LPSs showed no protein and showed the smear characteristic of smooth LPSs (8). A total of $375 \mu \mathrm{g}$ of each LPS was dispersed by sonication in $1.5 \mathrm{ml}$ of $10 \mathrm{mM}$ phosphate-buffered saline ( $\mathrm{pH} 7.2$ ), and the fluorescence was measured before and after NPN addition as described for whole cells. For $E$. coli LPS, fluorescence increased from 4 

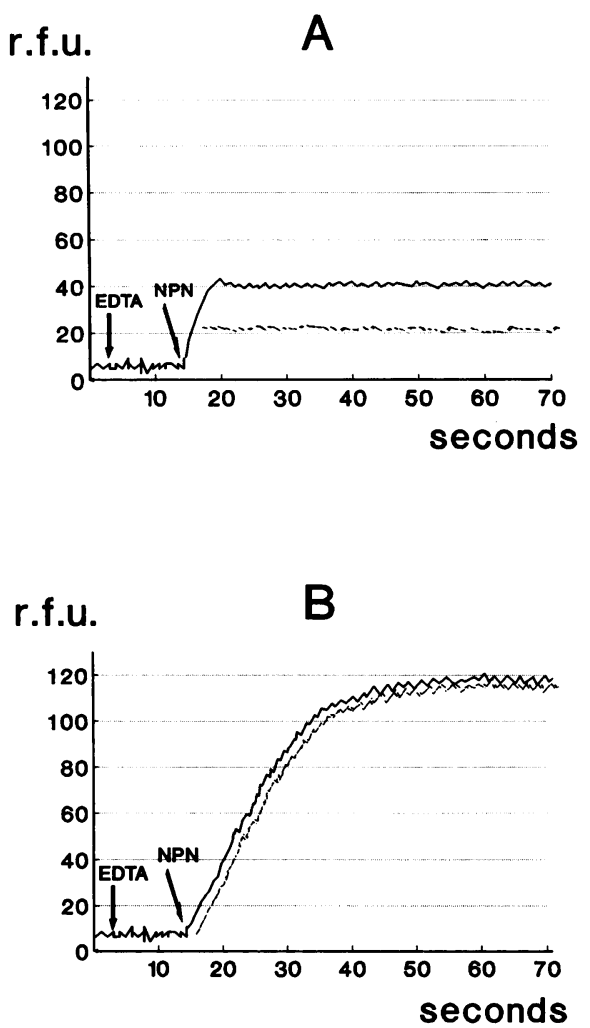

FIG. 2. Effect of $5 \mathrm{mM}$ EDTA on the uptake of NPN by whole bacterial cells. (A) E. coli 0111 K58 H2; (B) B. abortus 2308. Discontinuous lines in both panels represent the results of control experiments performed without addition of EDTA.

to 27 RFU, roughly $30 \%$ of the fluorescence obtained with $B$. abortus 2308 LPS (4 to 90 RFU).

In wild-type gram-negative bacteria, the impermeability to hydrophobic drugs is due to the LPS, which excludes the phospholipids from the outer leaflet of the OM, and when phospholipids are present in this leaflet (as in heptoseless mutants) the barrier is no longer effective (14). Thus, although our experiments point to a direct role of Brucella LPS in the absence of the barrier to hydrophobic permeants, exposure of phospholipid on the outer surface is also a possible factor. Compared with that in rough Brucella spp., the access of antibody to OM proteins is hindered in smooth Brucella spp. (15), but this does not mean that the smooth LPS covers all areas where proteins are exposed, since scattered patches of immunogold label are detected on intact smooth cells with antibodies to OM proteins $(2,5)$. This is compatible with an OM model in which dispersed phospholipid patches alternate with larger areas covered by the smooth LPS. If so, such patches could also play a role in the partition of hydrophobic permeants into the OM of Brucella spp.

We express our gratitude to U. Seydel and G. Schmidt for the $S$. minnesota rough mutants and to $G$. Schurig for the $B$. abortus RB51 mutant.

This research was supported by the Dirección General de Inves- tigación Científica y Tecnológica of Spain (grant PM92-0140-CO2) and by Fundación R. Areces. Fellowship support for G.M.T. from the Ministerio de Educación y Ciencia of Spain is also acknowledged.

\section{REFERENCES}

1. Brandenburg, K., and U. Seydel. 1984. Physical aspects of structure and function of membranes made from lipopolysaccharides and free lipid A. Biochim. Biophys. Acta 775:225-238.

2. Cloeckaert, A., P. de Wergifosse, G. Dubray, and J. N. Limet. 1990. Identification of seven surface-exposed Brucella outer membrane proteins by use of monoclonal antibodies: immunogold labelling for electron microscopy and enzyme-linked immunosorbent assay. Infect. Immun. 58:3980-3987.

3. Corbel, M. J., and W. J. Brinley-Morgan. 1984. Genus Brucella Meyer and Shaw $1920,173^{\mathrm{AL}}$, p. 377-388. In N. R. Krieg and J. G. Holt (ed.), Bergey's manual of systematic bacteriology, vol. 1 . The Williams \& Wilkins Co., Baltimore.

4. Douglas, J. T., E. Y. Rosenberg, H. Nikaido, D. R. Verstreate, and A. J. Winter. 1984. Porins of Brucella species. Infect. Immun. 44:16-21.

5. G6mez-Miguel, M. J., I. Moriyón, and J. Lopez. 1987. Brucella outer membrane lipoprotein shares antigenic determinants with Escherichia coli Braun lipoprotein and is exposed on the cell surface. Infect. Immun. 55:258-262.

6. Hancock, R. E. W. 1984. Alterations in outer membrane permeability. Annu. Rev. Microbiol. 38:237-264.

7. Hancock, R. E. W. 1988. Uptake of antibiotics into gramnegative bacteria. Eur. J. Clin. Microbiol. Infect. Dis. 7:713720.

8. Hitchcock, P. J., L. Leive, P. H. Mäkelä, E. T. Rietschel, W. Strittmatter, and D. C. Morrison. 1986. Lipopolysaccharide nomenclature - past, present, and future. J. Bacteriol. 166:699_ 705.

9. Leong, D., R. Diaz, K. Milner, J. Rudbach, and J. B. Wilson. 1970. Some structural and biological properties of Brucella endotoxin. Infect. Immun. 1:174-182.

10. Martin, N. L., and R. E. W. Hancock. 1990. Function and structure of the major components of the outer membrane of gram-negative bacteria, p. 55-75. In L. G. Adams (ed.), Advances in brucellosis research. Texas A\&M University Press, College Station.

11. Moreno, E., E. Stackebrandt, M. Dorsch, J. Wolters, M. Busch, and H. Mayer. 1990. Brucella abortus 16S rRNA and lipid A reveal a phylogenetic relationship with members of the alpha-2 subdivision of the class Proteobacteria. J. Bacteriol. 172:35693576.

12. Moriyon, I., and D. T. Berman. 1982. Effects of nonionic, ionic, and dipolar ionic detergents and EDTA on the Brucella cell envelope. J. Bacteriol. 152:822-828.

13. Nikaido, H. 1976. Outer membrane of Salmonella typhimurium. Transmembrane diffusion of some hydrophobic substances. Biochim. Biophys. Acta 433:118-132.

14. Nikaido, H., and M. Vaara. 1985. Molecular basis of bacterial outer membrane permeability. Microbiol. Rev. 49:1-32.

15. Riezu-Boj, J. I., I. Moriyón, J. M. Blasco, C. Gamazo, and R. Diaz. 1990. Antibody response to Brucella ovis outer membrane proteins in ovine brucellosis. Infect. Immun. 58:489-494.

16. Sawyer, J. G., N. L. Martin, and R. E. W. Hancock. 1988. Interaction of macrophage cationic proteins with the outer membrane of Pseudomonas aeruginosa. Infect. Immun. 56:693698.

17. Träuble, H., and P. Overath. 1973. The structure of Escherichia coli membranes studied by fluorescence measurements of lipid phase transitions. Biochim. Biophys. Acta 307:491-512.

18. Tsai, C., and C. E. Frasch. 1982. A sensitive stain for detecting lipopolysaccharides in polyacrylamide gels. Anal. Biochem. 119:115-119. 